\title{
Prospective study of factors predicting uptake of smoking in adolescents
}

\author{
A D McNEILL, ${ }^{1}$ M J JARVIS, ${ }^{1} \mathrm{~J}$ A STAPLETON, ${ }^{1} \mathrm{M}$ A H RUSSELL, ${ }^{1} \mathrm{~J}$ R EISER, ${ }^{2}$ \\ P GAMMAGE, ${ }^{3}$ AND E M GRAY ${ }^{4}$ \\ From ${ }^{1}$ the Addiction Research Unit, Institute of Psychiatry, London SE5; ${ }^{2}$ the Department of Psychology, \\ University of Exeter; ${ }^{3}$ the School of Education, University of Nottingham; and ${ }^{4}$ the School of Education, University \\ of Bristol
}

\begin{abstract}
Risk factors for the uptake of cigarette smoking were examined prospectively in 2159 non-smoking secondary schoolchildren aged 11-13 who participated in a survey in 1983 and were followed up 30 months later, by which time 35 per cent had taken up smoking. In a multivariate logistic model, the strongest predictors to emerge were prior experimentation with cigarettes and sex, with more girls $(41 \%)$ than boys $(30 \%)$ starting to smoke. Other predictors of taking up smoking were being uncertain about smoking in the future, reporting having been drunk, having a boy or girl friend, believing teachers and friends would not mind if they took up smoking, and giving lower estimates of prevalence of smoking among teachers. Parental smoking behaviour and attitudes, $\vec{\Phi} \mathrm{N}$ beliefs about the effects of smoking on health, opinions about smoking and perceived strictness of parents did not predict take up of smoking when other variables were controlled for. The odds of taking up smoking varied from $0 \cdot 24$ (risk $=0 \cdot 19$ ) for a child with the most favourable combination of risk factors to 3.49 (risk $=0.78$ ) for a child with the worst prognosis. These results differ from those of many cross sectional studies and hence indicate the importance of a prospective approach to this type of research.
\end{abstract}

Most cigarette smokers take up the habit during adolescence. A recent UK national survey indicated that the proportion of regular smokers increases sharply between the first and fifth years of secondary school and that $40 \%$ of sixteen year olds smoke. ${ }^{1}$ It is important to be able to identify those children most likely to take up smoking during these school years.

The following factors have emerged from British studies as being associated with smoking: parental smoking and precept; sibling and peer smoking; social class; pocket money; alcohol consumption; truancy; lower academic achievement; participation in social activities associated with older and mixed sex peer groups; rejection of the health hazards associated with smoking; and personality characteristics such as rebelliousness, neuroticism and extraversion. ${ }^{2-9}$ However, most of these studies were cross sectional in design and it is not clear whether the factors identified actually predated the uptake of smoking or were merely concomitants. Also these cross sectional studies have not been able to separate factors associated with smokers who have recently acquired the habit from those affecting long standing smokers. ${ }^{10}$ Prospective studies should be more informative, although when smokers are included in the baseline sample, ${ }^{7}$ they suffer from similar interpretative problems.

Prospective studies of adolescent smoking carried out in the United States have found future intention to smoke to be a predictor of the onset of adolescent smoking in addition to various combinations of the above factors. ${ }^{11-17}$ Results obtained from univariate analyses have conflicted with those derived from a multivariate approach. ${ }^{18}$

This paper presents the results of a prospective study of the onset of adolescent smoking in a representative sample of non-smoking secondary school children. Self reports of smoking status were supported by a biochemical marker (saliva cotinine), unlike most surveys which have relied on self reports only. It has been suggested that informing students that such objective measures of smoking will be used increases the level of reported smoking. ${ }^{19}$ Sociodemographic and attitude-belief variables were 
used to model future changes in smoking behaviour both univariately and multivariately.

\section{Methods}

In April 1983, 10579 pupils (all those present on the days of the survey) aged 11 to 16 years from 10 mixed secondary schools selected at random from the Bristol area filled in an extensive questionnaire on smoking. Before completing the questionnaires, the children were informed that a random sample of them would be asked to provide a saliva sample which would be analysed to detect smoking. The questionnaires were then administered by 26 trained research assistants, following a carefully standardised procedure. To ensure that a substantial proportion of the smokers in each of the school years provided a saliva sample, 750 , $600,527,434$ and 346 pupils ( $25 \%$ of the total) were randomly selected from the first to fifth years respectively. Methodological details of the first survey have been described elsewhere. ${ }^{9}$

A follow up survey was carried out some 30 months later in November 1985 in nine of the schools, one school being unable to take part because of industrial action. The survey targeted children who had been in the first and second years and aged 11-13 in 1983 and were now in the fourth and fifth years and aged 14-16. Procedures were the same as in the 1983 survey except that a shortened version of the original questionnaire was used and saliva samples were collected from all participants.

The measure of smoking behaviour was a version of Bewley's scale ${ }^{20}$ in which subjects assigned themselves to one of the following categories: "I have never smoked a cigarette, not even a puff"; "I have only ever tried smoking once or twice"; "I used to smoke sometimes but I don't now"; "I smoke sometimes but don't smoke as much as one cigarette a week"; "I usually smoke between one and six cigarettes a week"; "I usually smoke more than six cigarettes a week".

Parental socio-economic group was determined according to the Registrar General's classification of occupations. ${ }^{21}$ The social class distribution (according to fathers' occupation) of the original and follow up samples closely matched national figures.

Smoking behaviour of parents, siblings and boy/girl friend were recorded, and attitudes of role models towards smoking were determined by the questions: "Would your father/mother/teachers/best friends mind if they saw you smoking?" ("Very Much", "Quite a bit", "A little," "Not at all").

Self prediction of future smoking was assessed by two questions: "Do you think you will smoke one year from now?" and "Do you think you will smoke when you leave school for good?" ("Yes", "Perhaps", "No"). These two items were combined to form one variable of intention to smoke at some time in the future.

Beliefs about the effect of smoking on health (6 items), opinions about smoking (13 items) and perceived strictness of parents ( 9 items) were covered in detail. When factor analysed, two factors on health beliefs emerged which explained $51 \%$ of the variance, covering beliefs about the short term and long term harmful effects of smoking. Four factors emerged which explained $51 \%$ of the variance in opinions about smoking, namely having a negative view of smoking, believing that smoking had a tough image, believing that people smoke for pharmacological effects, and that young people smoke to annoy adults. Finally, two factors emerged which explained $61 \%$ of the variance in perceived strictness of parents. The first was viewing parents as too strict and the second was believing themselves to be autonomous of parental control.

Perception of school achievement was measured by the following question: "How do you think you are doing in your school work?" ("Very well" "Quite well", "Average", "Not very well", "Badly"). Subjects were also asked how many children in their school year and how many teachers in their school they thought smoked. School policy towards smoking was covered by whether they thought that their school had strict rules about smoking, by recall of lessons and assemblies on smoking, and by whether staff were seen smoking in the staff room or around the school. Questions also covered amount of pocket money and alcohol use. A copy of the full questionnaire is available from the authors on request.

A total of 3513 children participated in 1985, of whom 2938 had been present in 1983 . This represented a follow up rate of 77 per cent of eligible subjects. Losses to follow up were due to illness, truancy, or having moved to another school. Children lost to follow up differed from respondents in a number of ways. In particular, $16 \%$ of those 11 and 12 years olds not followed up reported some current smoking in 1983 as against $9 \%$ of those who were followed up $(p<0.001)$. Even when the analysis was restricted to the 1983 never smokers or triers there were significant differences in parental smoking behaviour, attitude of exemplars, perceived achievement at school and drinking habits. The differences suggest some caution in generalising the present results to all adolescents of this age.

\section{BIOCHEMICAL ANALYSIS}

A random sample of the 1983 saliva samples were analysed for cotinine by gas chromatography. ${ }^{22}$ Of those adolescents who in 1983 reported being never smokers or having tried smoking once or twice and were present in both surveys, there were 216 with 
measured cotinine concentrations. Only one of these cotinine concentrations fell above a non-smoker/ smoker optimal cut off of $14.3 \mathrm{ng} / \mathrm{ml},{ }^{23}$ suggesting a low deception rate. This individual had a value of $17 \cdot 4$ $\mathrm{ng} / \mathrm{ml}$ which could conceivably have resulted from heavy passive smoke exposure. ${ }^{24}$ Based on these results, it was not considered necessary to make adjustments to self reports of smoking status.

\section{STATISTICAL ANAL YSES}

Data were analysed using the SPSSX and SAS statistical packages. The importance of potential risk factors was assessed by fitting logistic regression models using the SAS Logist Procedure. ${ }^{25}$

\section{Results}

SMOKING PREVALENCE IN 1983 AND 1985

Smoking prevalence (defined as any level of current smoking) by age and sex in 1983 and 1985 in the nine schools which participated in both surveys is given in table 1. The 1983 data give a clear picture of the build up of smoking with age. Approximately $10 \%$ of the 11 to 12 year old boys and girls were smoking. At the age of 13 a sharp increase in smoking prevalence is seen, with girls significantly exceeding boys $\left(22 \% v 14 \%, \chi^{2}\right.$ $22.8, \mathrm{p}<0.001)$. This increase in smoking prevalence continues among 14 and 15 year olds with the girls remaining at a significantly higher level. However, by age 16, the boys appear to have almost attained the more stable level reached earlier by the girls. There is some indication in these data that after the age of 12 , boys lag behind the girls by approximately one year in the uptake of smoking. It can be seen that there was no change in the prevalence of smoking from 1983 to 1985 for either sex among those ages represented in both surveys.

\section{PREDICTING UPTAKE OF SMOKING}

The baseline and follow up smoking status of the 2159 children who were aged 11 to 13 in 1983 and reported that they had never smoked or had tried smoking once or twice is shown in table 2. By $1985,35 \%$ reported having taken up smoking ("smokers", $n=763$ ). Of

Table 1 Smoking prevalence (\%) by age and sex in 1983 and 1985 in the nine schools which participated in both surveys. Sample sizes in parentheses

\begin{tabular}{|c|c|c|c|c|c|c|c|c|}
\hline & & $\begin{array}{l}\text { Age (years) } \\
\text { II }\end{array}$ & 12 & 13 & 14 & 15 & 16 & Total \\
\hline \multirow{2}{*}{1983} & Boys & $\begin{array}{c}10 \\
(357)\end{array}$ & $\begin{array}{c}11 \\
(984)\end{array}$ & $\begin{array}{r}14 \\
(1003)\end{array}$ & $\begin{array}{r}24 \\
(1041)\end{array}$ & $\begin{array}{c}29 \\
(987)\end{array}$ & $\begin{array}{c}36 \\
(608)\end{array}$ & $\begin{array}{r}21 \\
(4980)\end{array}$ \\
\hline & Girls & $\begin{array}{c}9 \\
(342)\end{array}$ & $\begin{array}{c}11 \\
(956)\end{array}$ & $\begin{array}{c}22 \\
(910)\end{array}$ & $\begin{array}{c}33 \\
(915)\end{array}$ & $\begin{array}{c}38 \\
(922)\end{array}$ & $\begin{array}{r}40 \\
(533)\end{array}$ & $\begin{array}{r}26 \\
(4578)\end{array}$ \\
\hline \multirow{2}{*}{1985} & Boys & & & & $\begin{array}{c}24 \\
(738)\end{array}$ & $\begin{array}{c}29 \\
(854)\end{array}$ & $\begin{array}{c}38 \\
(201)\end{array}$ & $\begin{array}{r}28 \\
(1793)\end{array}$ \\
\hline & Girls & & & & $\begin{array}{c}35 \\
(715)\end{array}$ & $\begin{array}{c}39 \\
(826)\end{array}$ & $\begin{array}{c}41 \\
(152)\end{array}$ & $\begin{array}{r}37 \\
(1693)\end{array}$ \\
\hline
\end{tabular}

Table 2 Smoking status of the prospective sample

\begin{tabular}{|c|c|c|c|c|c|}
\hline & & \multicolumn{4}{|c|}{1985 self reported smoking status } \\
\hline & & \multicolumn{2}{|c|}{ "Non-Smokers" } & \multicolumn{2}{|l|}{ "Smokers" } \\
\hline & & $\begin{array}{l}\text { Never } \\
\text { smoked } \\
(n=718)\end{array}$ & $\begin{array}{l}\text { Tried once } \\
\text { or twice } \\
(n=678)\end{array}$ & $\begin{array}{l}\text { Used to } \\
\text { smoke } \\
(n=326)\end{array}$ & $\begin{array}{l}\text { Current } \\
\text { smoker } \\
(n=437)\end{array}$ \\
\hline \multirow[t]{2}{*}{$\begin{array}{l}1983 \text { self } \\
\text { reported } \\
\text { smoking status }\end{array}$} & $\begin{array}{l}\text { Never } \\
\text { smoked } \\
(1261)\end{array}$ & $\begin{array}{l}652 \\
(52 \%)\end{array}$ & $\begin{array}{l}337 \\
(27 \%)\end{array}$ & $\begin{array}{l}131 \\
(10 \%)\end{array}$ & $\begin{array}{l}141 \\
(11 \%)\end{array}$ \\
\hline & $\begin{array}{l}\text { Tried once } \\
\text { or twice } \\
(898)\end{array}$ & $\begin{array}{l}66 \\
(7 \%)\end{array}$ & $\begin{array}{l}341 \\
(38 \%)\end{array}$ & $\begin{array}{l}195 \\
(22 \%)\end{array}$ & $\begin{array}{l}296 \\
(33 \%)\end{array}$ \\
\hline
\end{tabular}


these, $43 \%$ reported that they used to smoke, implying that they had taken it up since 1983 but were currently not smoking. They were included with the other "smokers" because the majority of those who said they "used to smoke" in 1983 had resumed smoking again by 1985 . When the analyses were repeated excluding those who "used to smoke" from the "smokers" category, very similar results were obtained.

In this prospective cohort, $52 \%$ of the children were male, $20 \%$ aged $11,53 \%$ aged 12 and $27 \%$ aged 13 . Thirty five per cent fell in the non-manual socioeconomic group, as determined by their reports of fathers' occupation. In 1983, 38\% reported having a father who smoked, $33 \%$ a mother who smoked and $18 \%$ stated that they had a boy/girl friend.

\section{UNIVARIATE ANALYSES}

The association of questionnaire items from 1983 with subsequent change in smoking behaviour was first examined univariately. Of the 37 items examined, 24 predicted uptake of smoking (table 3 ).

The strongest predictor was prior experimentation with smoking (odds ratio 4.4). Children who thought they would definitely be smoking in the future $(1 \%$, $\mathrm{n}=23$ ) or who were uncertain about future smoking

Table 3 Univariate analyses of variables related to change in smoking status

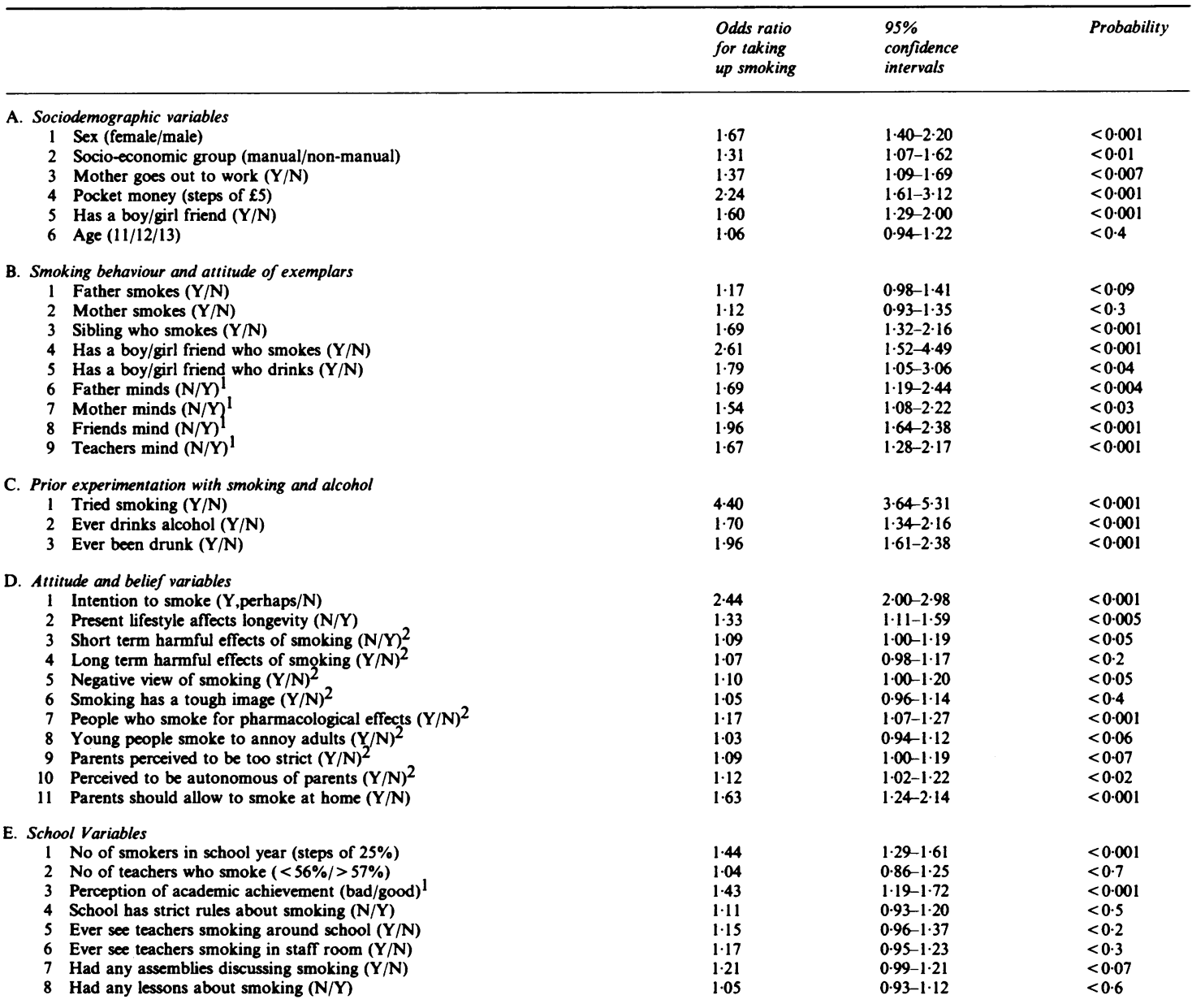

Note: $\mathrm{n}$ varies from 2062 to 2154 because of missing values on some questionnaire items, except for the following items where $\mathrm{n}$ is as specified: $\mathrm{A} 2: 1774$; 4 : 1448 ; $\mathrm{E} 5: 1848$; E6:1861; E7:1833; E8:1862.

${ }^{1}$ For these items, yes means very or quite a bit, no means a little or not at all. Bad means average or below average, good means above average

2 These variables are factor scores as described in the text. 
$(24 \%, \mathrm{n}=511)$ were more likely to have taken up smoking than those who could not see themselves smoking in the future (odds ratio 2.44 ).

A higher proportion of girls than of boys had started smoking in the follow up period. Reports of having larger amounts of pocket money and having a boy/girl friend (particularly if he/she was a smoker) were also positively associated with future smoking. Parental smoking habits did not predict taking up smoking but having a sibling who smoked did. Believing that parents, friends or teachers would mind only "a little" or "not at all" if they smoked was also related to future smoking uptake.

Those taking up smoking were more likely to have earlier reported drinking alcohol, having been drunk and having a boy/girl friend who drank. Other predictors of taking up smoking were manual socioeconomic group, reporting that mother went out to work, giving larger estimates of the number of smokers in the school year and lower ratings of personal academic achievement. Among a number of attitude/belief predictors were: believing that present lifestyle does not affect longevity, disagreeing that smoking has adverse short term health effects, having a negative view of smoking, agreeing that people smoke for pharmacological effects, perceiving themselves to be more autonomous of their parents and agreeing that the latter should allow children to smoke at home.

\section{MULTIVARIATE LOGISTIC ANALYSIS}

Due to the large number of intercorrelated predictor variables, a multivariate model was constructed to identify the most salient risk factors and the most parsimonious model for predicting the uptake of smoking. Missing data on the five questions concerning school policy towards smoking (E4-E8, table 3) would have caused a great reduction in the sample size and these items were therefore excluded from these analyses. However, they were not significant predictors when considered univariately. First, backward elimination was used to assess the importance of quadratic effects and first order interactions. Higher order interactions were not tested. Due to the large number of potentially important interactions a block reduction method was employed using a $1 \%$ significance level. By this method interactions were tested within and between each of the pairs of blocks (labelled A-E in table 3) jointly with all main effects but no other interactions present. After this initial elimination process all remaining interactions were entered into the complete model and elimination was allowed along with main effects. The final model consisted of three interactions and nine other noninteracting variables (model $\chi^{2}=338.45,18 \mathrm{df}$, $\mathrm{p}<0.001$; residual $\chi^{2}=25.65,17 \mathrm{df}, \mathrm{p}<0.09$ ).
None of the health beliefs about smoking, opinion about smoking or beliefs about parents emerged as significant predictors, although these items were involved in the significant interactions. Owing to the fact that three interactions were well below the number expected significant by chance when carrying out so many tests, a main effects only model was also examined, again using backward elimination. The non-interaction part of the original model remained very much the same although one variable, giving larger estimates of the number of smokers in the school year, was no longer a significant predictor (model $\chi^{2}=298.0,8 \mathrm{df}, \mathrm{p}<0.001 ;$ residual $\chi^{2}=33.3$, $24 \mathrm{df}, \mathrm{p}<0 \cdot 1)$. None of the eight significant main effect variables gave rise to significant interactions. Thus we did not detect differences in factors predictive of the uptake of smoking as between girls and boys, older and younger children, or never smokers and those who had tried smoking once or twice. The results of this analysis are given in table 4 .

Table 4 Multivariate logistic regression analysis using main effects only for predicting change in smoking status $(n=1574 \vec{D} \mathrm{~N}$

\begin{tabular}{llll} 
& $\begin{array}{l}\text { Odds } \\
\text { Ratio }\end{array}$ & $\begin{array}{l}95 \% \\
\text { Confidence } \\
\text { intervals }\end{array}$ & $\begin{array}{l}\text { Proba- } \\
\text { bility }\end{array}$ \\
\hline Tried smoking (Y/N) & 4.03 & $3.17-5.14$ & $<0.001$ \\
Sex (female/male) & 2.54 & $1.99-3.26$ & $<0.001$ \\
Intention to smoke (Y,perhaps/N) & 1.69 & $1.31-2.20$ & $<0.001$ \\
Ever been drunk $(\mathrm{Y} / \mathrm{N})$ & 1.67 & $1.29-2.17$ & $<0.001$ \\
Has a boy/girl friend $(\mathrm{Y} / \mathrm{N})$ & 1.61 & $1.20-2.16$ & $<0.001$ \\
Teachers mind $(\mathrm{N} / \mathrm{Y})$ & 1.72 & $1.20-2.44$ & $<0.005$ \\
Friends mind (N/Y) & 1.37 & $1.06-1.79$ & $<0.05$ \\
No of teachers who smoke $(<56 \% />57 \%)$ & 1.35 & $1.05-1.72$ & $<0.05$ \\
\hline
\end{tabular}

Prior experimentation with cigarettes was again the strongest predictor, with those who had tried smoking having odds four times greater than never smokers of having taken up smoking 30 months later. The next strongest predictor was sex, with girls having 2.5 times the odds of boys of becoming smokers. Other significant predictors were being uncertain about smoking in the future, reporting having been drunk, having a girl/boy friend and believing that teachers and friends would mind less if they smoked. Giving smaller estimates of the number of teachers who smoked also indicated that the adolescent was more likely to take up smoking in the future.

Many of the variables which were significant univariately did not contribute to the multivariate model. Amongst these were having a boy/girl friend who smoked (which by definition had a high correlation with having a boy/girl friend) and ever 
drinking alcohol (similarly related to the more predictive item, having ever been drunk). Believing people smoke for pharmacological effects, that parents should allow children to smoke, giving higher estimates of the number of smokers in the school year and lower perception of personal academic achievements were all correlated with having tried smoking and uncertainty about future smoking. The variable "estimate of numbers of teachers who smoke" was marginally significant in the multivariate model whereas it had not predicted univariately. This was due to its negative correlation with having tried smoking and uncertainty about future smoking. It should be remembered that this variable, together with believing that friends would not mind if they smoked only just achieved significance at the $5 \%$ level, and one or two such results would have been expected by chance when examining 32 variables.

From the final main effects only model, a child having the most favourable combination of factors for not taking up smoking had estimated odds of $0 \cdot 24$ (risk $=0 \cdot 19$ ) compared to a child with the least favourable combination of factors, who had odds of 3.49 (risk $=0.78$ ), giving an odds ratio for these children of 14.56 (relative risk $=4 \cdot 1$ ).

\section{Discussion}

In this study a number of behavioural and demographic factors measured among non-smoking schoolchildren aged 11-13 predicted their taking up smoking in the next two and a half years. In a multivariate model, the two factors most strongly associated with the subsequent onset of smoking were prior experimentation with cigarettes and being a girl. Among children who had already tried one or two cigarettes in 1983 the odds of taking up smoking were more than four times those among the never smokers. This indicates that trying cigarettes makes a child much more vulnerable to becoming a smoker, and suggests that intervention efforts with younger children should aim at discouraging all experimentation, even a puff. However, as a substantial number of secondary schoolchildren have already tried smoking, interventions with this age group (11-16 years old) need also to deal with interrupting the development of smoking before dependence sets in. Interactions between trying smoking and the other predictor variables did not emerge as significant, suggesting that there were no major differences in the predictors for never smokers and triers. However, the issue of predictors involved in the progression from never smoking to trying one or two cigarettes will be addressed in a second paper.

Although similar proportions of boys and girls reported some smoking at age 11-13, 41 per cent of girls compared with 30 per cent of boys were smoking 30 months later. The trend towards a higher smoking prevalence in girls confirms findings from other surveys in the UK, ${ }^{826}$ and does not appear to be restricted to British schoolchildren. ${ }^{16}$ The reasons underlying the emerging trend for more girls to smoke than boys are not clear, as none of the interactions with sex emerged as significant in the context of the overall model. Our results indicate that more research is needed to investigate how anti-smoking interventions could be adapted to be more relevant to girls. There was however an indication in our data that the girls were simply taking up smoking at an earlier age than boys.

The finding that having been drunk and having a boy/girl friend were significant predictors of taking up smoking lends support to Bynner's model, ${ }^{3}$ in which the factor "anticipation of adulthood" (a measure of the extent of a boy's participation in activities such as dating, going out drinking with friends and going to coffee bars or dance halls) was found to be important, but extends this result to girls.

As with other research findings, uncertainty about remaining a non-smoker was an important predictor of taking up smoking, as was also the perceived attitude of friends. This indicates the appropriateness of preventive measures which incorporate a commitment not to smoke in the future and focusing on resisting peer pressure to smoke.

Those children who thought that their teachers would mind if they smoked were less likely to take up smoking, indicating that for this age group teachers' attitude towards children's smoking may be important. However, teachers may be acting as counter role models, as those children believing that more teachers smoked were less likely to take up smoking themselves.

The findings of this study differ from those based on cross sectional surveys in several ways. First, the attitudes and beliefs about smoking measured here were not identified as important predictors of future behaviour change. This questions the role of health education programmes which are designed to modify behaviour via a change in attitudes. Although health education is essential to equip children with sound reasons for not smoking, it is apparent that other factors can override any such anti-smoking attitudes of beliefs.

Secondly, family smoking and parental strictness or attitude towards their children's smoking were not significant predictors of taking up smoking in the prospective multivariate analysis. Although it is possible that behaviour and attitude of family members may affect the smoking behaviour of younger children (ie, those taking up smoking before age 11-13), if a child succeeds in resisting smoking until secondary school age, other factors (eg, perceived 
disapproval from teachers or the peer group) seem to have a greater predictive value. Another point of interest is that although there is a marked socioeconomic gradient in smoking prevalence in adults, we found no effect multivariately of parental socioeconomic group on smoking uptake in these adolescents.

This study has identified those adolescents most at risk of taking up smoking in a 30 month period. As might be expected, although a large number of predictors (24) were associated with taking up smoking in a univariate analysis, relatively few made a significant contribution to the multivariate models. It is useful to know that relatively objective questions, for example previous cigarette and alcohol use, are better predictors than health beliefs or attitude questions.

This study forms part of the Health Education Council's Smoking Education for Teenagers project. We are grateful to the schools concerned for their cooperation. Financial support was provided by the Health Education Council and the Medical Research Council.

Address for correspondence and reprints: Ann D McNeill, Institute of Psychiatry, Addiction Research Unit, 101 Denmark Hill, London SE5 8AF.

\section{References}

${ }^{1}$ Dobbs J, Marsh A. Smoking among secondary school children in 1984. London: HMSO, 1985.

2 McKennell AC, Thomas RK. Adults' and adolescents' smoking habits and attitudes. London: HMSO, 1967.

3 Bynner JM. The Young Smoker. London: HMSO, 1969.

${ }^{4}$ Cherry N, Kiernan K. Personality scores and smoking behaviour. Br J Prev Soc Med 1976; 30: 123-31.

${ }^{5}$ Bewley BR. Smoking in Childhood. Postgrad Med J 1978; 54: 197-8.

${ }^{6}$ Mangan GL, Golding JF. Factors underlying smoking recruitment and maintenance among adolescents. $A d v$ Behav Res Ther (1983); 4: 225-72.

${ }^{7}$ Murray M, Swan AV, Bewley BR, Johnson MRD. The development of smoking during adolescence-the MRC/ Derbyshire smoking study. Int J Epidemiol 1983; 12: 185-92.

${ }^{8}$ Charlton A. The Brigantia smoking survey: a general review. Public education about cancer. UICC Technical Report Series, Vol. 77. Geneva: Union Internationale Contre le Cancer, 1984.

${ }^{9}$ Nelson SC, Budd RJ, Eiser JR, Morgan M, Gammage P, Gray E. The Avon prevalence study: a survey of cigarette smoking in secondary schoolchildren. Health Educ $J$ $1985 ; 44: 12-5$.
${ }^{10}$ Chassin L, Presson CC, Sherman SJ, Montello D, McGrew J. Changes in peer and parent influence during adolescence: Longitudinal versus cross-sectional perspectives on smoking initiation. Devel Psychol 1986; 22: 327-34.

${ }^{11}$ Salber EJ, Abelin T. Smoking behaviour of Newton schoolchildren-five year follow up. Pediatrics 1967; 40: 363-72.

12 National Institute of Education. Teenage smoking: immediate and longterm patterns. Washington, D.C.: US Government Printing Office, 1979.

${ }^{13}$ McCaul K, Glasgow R, O'Neill HK, Freeborn V, Rump BS. Predicting adolescent smoking. J School Health 1982; 8: $342-6$.

${ }^{14}$ Ary DV, Biglan A, Gallison CL, Weissman W, Severson $\mathrm{HH}$. Longitudinal prediction of the onset and change of adolescent smoking. In: Forbes WE, Frecker RC, Nostbakken D, eds. Proceedings of the 5th World Conference Smoking and Health, vol 1. Winnipeg, Canada, 1983.

${ }^{15}$ Chassin L, Pressin CC, Sherman SJ, Corty E, Olshavsky RW. Predicting the onset of cigarette smoking in adolescents: a longitudinal study. J Appl Soc Psychol 1984; 14: $224-43$.

16 Pederson LL, Lefcoe NM. Change in smoking status among a cohort of late adolescents: prediction and explanation of initiation, maintenance and cessation. Int

17 Mittelmark MB, Murray DM, Luepker RV, Pechacek JF Pirie PL, Pallonen UE. Predicting experimentation with cigarettes. The childhood antecedents of smoking studp 음 (CASS). Am J Public Health 1987; 77: 206-8.

${ }^{18}$ Allegrante JP, O'Rourke TW, Tunclap S. A multivariate analysis of selected psychosocial variables on the development of subsequent youth smoking behaviour. $\$$ Drug Educ 1977; 7: 237-48.

19 Murray DM, O'Connell CM, Schmid LA, Perry CL. The validity of smoking self-reports by adolescents: reexamination of the bogus pipeline procedure. Addic Behav 1987; 12: 7-15.

${ }^{20}$ Bewley BR, Bland JM, Harris R. Factors associated with the starting of cigarette smoking by primary school children. Brit J Prev Soc Med 1974; 28: 37-44.

21 Office of Population Censuses and Surveys. Classification of occupations. London: HMSO, 1980.

${ }^{22}$ Feyerabend C, Bryant AE, Jarvis MJ, Russell MAH Determination of cotinine in biological fluids of nonsmokers by packed column gas-liquid chromatography. $J$ Pharm Pharmacol 1986; 38: 917-9.

${ }^{23}$ McNeill AD, Jarvis MJ, West R, Russell MAH, Bryant A. Saliva cotinine as an indicator of cigarette smoking in adolescents. Br J Addict 1987; 82: 1355-60.

24 Jarvis MJ. Uptake of environmental tobacco smoke. In: O'Neill IK, Brunnemann KD, Dodet B, Hoffman D, eds. Environmental carcinogens: methods of analysis and exposure measurement, vol 9, Passive smoking, chapter 4. Lyon: IARC, 1987. (IARC Scientific Publications No. 81 ).

${ }^{25}$ Harrell FE. The LOGIST procedure. In: SUGI supplementary library users guide. Cary, North Carolina: SAS Institute Inc, 1983.

${ }^{26}$ Gillies P, Elwood JM, Pearson JCG, Cost G. An $\frac{D}{O}$ adolescent smoking survey in Trent, and its contribution to health promotion. Health Educ J 1987; 46: 19-22.

Accepted for publication November 1988 